\title{
Comparison of different strategies for treatment of duodenal ulcer
}

\author{
AMNON SONNENBERG
}

\begin{abstract}
A simple model of a Markov chain was used to study the long term outcome of different strategies for the treatment of duodenal ulcer. Maintenance treatment with $\mathrm{H}_{2}$ receptor antagonists surpassed intermittent drug treatment and proximal gastric vagotomy with respect to the relapse free interval and severe postoperative morbidity. With maintenance treatment the rate of complications and the number of deaths related to ulcer were slightly higher than after proximal gastric vagotomy. Nevertheless, because the few deaths from proximal gastric vagotomy occur at the initiation of treatment the loss of life years during maintenance treatment exceeded that of proximal gastric vagotomy only after 20 years. Despite its rarity, severe postoperative morbidity after proximal gastric vagotomy far exceeded that after the few emergency operations which would become necessary in the course of maintenance treatment. The superiority of maintenance treatment over proximal gastric vagotomy remained insensitive to changes in the assumptions underlying the recurrence rate with both treatments and the postoperative morbidity of proximal gastric vagotomy.
\end{abstract}

\section{Introduction}

There are at least three different strategies to treat duodenal ulcer disease: intermittent use of $\mathrm{H}_{2}$ receptor antagonists, use of $\mathrm{H}_{2}$ antagonists as maintenance treatment, and elective surgery by proximal gastric vagotomy. Intermittent treatment is started by the physician after examination of the patient with symptoms or by the patient himself as soon as he suspects relapse (on demand);

Division of Gastroenterology, Beth Israel Hospital, Boston, Massachusetts 02215, USA

AMNON SONNENBERG, MD, research associate treatment is stopped after two to four weeks. Maintenance treatment implies that an $\mathrm{H}_{2}$ receptor antagonist will be taken for years regardless of symptoms. In maintenance treatment the full dose is taken until the ulcer has healed, and the patient then continues with half the dose. I have used a simple model of a Markov chain' to study the effects of the three strategies on the proportion of healed ulcers and on the proportion of emergency operations performed for complications.

\section{Methods}

Any patient with duodenal ulcer may be considered to be in one of the following states: healed ulcer, recurrent ulcer, postoperative state, and dead (fig 1). The results of gastric surgery - that is, the postoperative state-may be further separated according to the scoring system suggested by Visick, grades I-III denoting a satisfactory outcome and grade IV an unsatisfactory outcome of surgery. ${ }^{2}$ The transitions among these states are governed by the probability of $(a)$ ulcer relapse, $(b)$ ulcer healing, and $(c)$ satisfactory, $(d)$ unsatisfactory, or $(e)$ lethal outcome of gastric surgery.

The healing and recurrence rates of duodenal ulcer were adopted from a compilation of clinical trials by Pounder. ${ }^{3}$ On average the recurrence rate and spontaneous healing rate are $8.5 \%$ and $43 \%$ per month. Maintenance treatment changes the recurrence rate from $8 \cdot 5 \%$ to $2 \cdot 5 \%$ per month; ulcers giving acute attacks treated with $\mathbf{H}_{2}$ antagonists change the healing rate from $43 \%$ to $77 \%$ per month.

The monthly death rate for each recurrent ulcer was adjusted to give a cumulative risk of $1.7 \%$ at nine years. This cumulative risk of dying reported by Bonnevie corresponds to a monthly death rate of $0.09 \%$ from all relapses of ulcer ${ }^{4}$ Haemorrhage $(H)$ occurs three times more often than perforation $(P)^{5-7}-\mathbf{H}=3 \mathrm{P}$. One third of bleeding ulcers $(B)$ and all perforated ulcers are operated on $-\mathrm{OP}=\mathrm{B} / 3+\mathrm{P}$. The overall mortality from haemorrhage and perforation is $15 \%^{8.9}$ - thus $15 \%(\mathrm{~B}+\mathrm{P})=0.09 \%$. From the three equations we can calculate the monthly incidence of emergency operations to be $0.3 \%$ of all relapses of duodenal ulcer and the mortality of emergency operations to be $30 \%$.

In an emergency partial gastrectomy or truncal vagotomy plus pyloroplasty is performed. Of patients surviving emergency operation, operative outcome is assumed to be unsatisfactory in $10 \% \cdot{ }^{10-13}$ From life table analysis of proximal gastric vagotomy a recurrence rate of $0.25 \%$ per month is 
estimated. ${ }^{14}$ An acute ulcer recurring after proximal gastric vagotomy is treated by $\mathrm{H}_{2}$ antagonists, the healing rate being the same as in the unoperated stomach. ${ }^{15}$ Death may be expected in three in 1000 operations. ${ }^{16}$ In $5 \%$ of patients the long term result of proximal gastric vagotomy will be unsatisfactory for reasons other than recurrent ulcer. ${ }^{11.13}$

In the sensitivity analysis of medical treatment recurrence rate and healing rate with $\mathrm{H}_{2}$ antagonists are varied from $1 \%$ to $4 \%$ and from $70 \%$ to $84 \%$ per month according to the range reported by different authors. ${ }^{17} 18$ The upper limits of a recurrence rate of $1 \%$ and healing rate of $84 \%$ were taken from two recent trials testing ranitidine. ${ }^{1920}$ Also the incidence of emergency operations is doubled. In the sensitivity analysis of surgical treatment the proportion of unsatisfactory results after proximal gastric vagotomy is varied from $2 \%$ to $8 \%$ and the monthly recurrence rate from $0.1 \%$ to $0.5 \%$. These ranges emerge from compilation of different studies of proximal gastric vagotomy ${ }^{21}$ and from the direct comparison of different surgeons at one surgical centre. ${ }^{22}$ The table summarises all rates of the Markov chain shown in fig 1 .

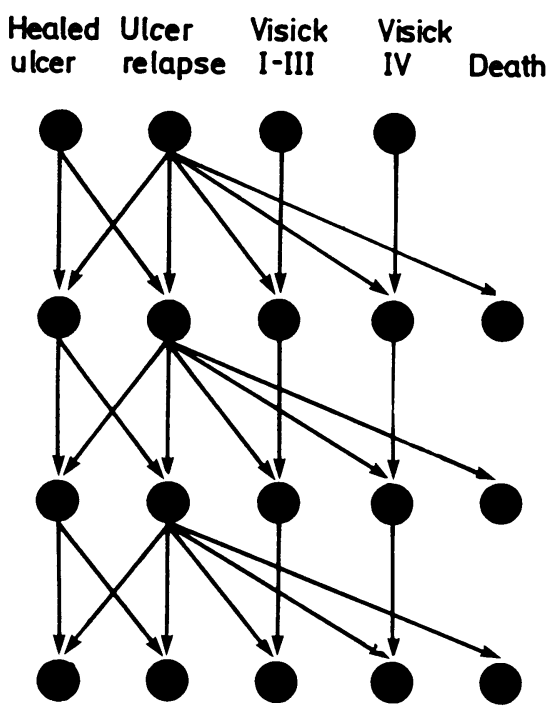

Ist month

FIG l-Markov state model of chronic duodenal ulcer.

The analysis is started with 100 hypothetical patients in the state of healed ulcer. The 100 patients are taken to represent the population of patients with duodenal ulcer, which means that in any one of these patients the diagnosis has been ascertained by duodenoscopy. It also means that in the large majority of these patients duodenal ulcer had already recurred several times, since this is the course of the disease in the average patient. Every month the patients are newly redistributed among the five states according to the transition probabilities. The monthly redistribution is continued for 40 years. After every five years the proportion of subjects in each state and the proportion of time spent in each of the five states are calculated.

\section{Results}

Figure 2 shows the effects of maintenance treatment, intermittent treatment, and no treatment on the proportion of time spent with a healed duodenal ulcer in the unoperated patients. While receiving maintenance treatment an average of $96 \%$ of the time is spent without recurrent ulcer. With intermittent treatment or without treatment only $86 \%$ and $78 \%$ of the time, respectively, is spent free of recurrent ulcer. With maintenance treatment the proportion of patients subjected to emergency operations increases from $0.6 \%$ after five years to $4 \cdot 4 \%$ after 40 years. Intermittent treatment and no treatment will increase this proportion of operated subjects threefold and fivefold respectively.

The outcome of maintenance treatment proves to be much more sensitive to changes of the monthly recurrence rate than to those of the healing rate (fig 3 (left), fig 4). After 20 years maintenance treatment will lead to premature death in $0.67 \%$ of subjects compared with $0.37 \%$ after proximal gastric vagotomy, but the fraction of $0.33 \%$ of time lost due to premature death will be similar with both treatments. This is because most deaths in patients given proximal gastric vagotomy occur at the initiation of treatment,
Rates and assumptions used in Markov chain in figure 1

\begin{tabular}{|c|c|c|}
\hline $\begin{array}{l}\text { Monthly rate and } \\
\text { results of surgery }\end{array}$ & $\begin{array}{c}\text { Baseline } \\
\text { assumption } \\
(\%)\end{array}$ & $\begin{array}{c}\text { Range used in } \\
\text { sensitivity analysis } \\
(\%)\end{array}$ \\
\hline $\begin{array}{l}\text { Spontaneous healing rate } \\
\text { Healing rate under } \mathrm{H}_{2} \text { blockade } \\
\text { Spontaneous recurrence rate } \\
\text { Recurrence rate under } \mathrm{H}_{2} \text { blockade } \\
\text { Recurrence rate after proximal gastric vagotomy } \\
\text { Incidence of emergency operation }\end{array}$ & $\begin{array}{l}43 \\
77 \\
8 \cdot 5 \\
2 \cdot 5 \\
0.25 \\
0 \cdot 3\end{array}$ & $\begin{array}{l}70-84 \\
\overline{1-4} \\
0 \cdot 1-0 \cdot 5 \\
0 \cdot 3-0 \cdot 6\end{array}$ \\
\hline $\begin{array}{l}\text { Results of emergency operation }{ }^{\star} \\
\text { Death }(30 \%) \\
\text { Visick grade IV }(7 \%) \\
\text { Visick grades I-III }(63 \%)\end{array}$ & $\begin{array}{l}0.09 \\
0.021 \\
0.189\end{array}$ & $\begin{array}{l}0.09-0.18 \\
0 \cdot 021-0.042 \\
0 \cdot 189-0.378\end{array}$ \\
\hline $\begin{array}{l}\text { Initial results of proximal gastric vagotomyt } \\
\text { Death } \\
\text { Visick grade IV } \\
\text { Visick grades I-III }\end{array}$ & $\begin{array}{c}0 \cdot 3 \\
5 \\
94 \cdot 7\end{array}$ & $\frac{\overline{2-8}}{97 \cdot 7-91 \cdot 7}$ \\
\hline
\end{tabular}

*In order to transform results of emergency operation to rates they are multiplied by incidence of

†After proximal gastric vagotomy only patients with Visick grades I-III are subjected to Markov chain analysis.
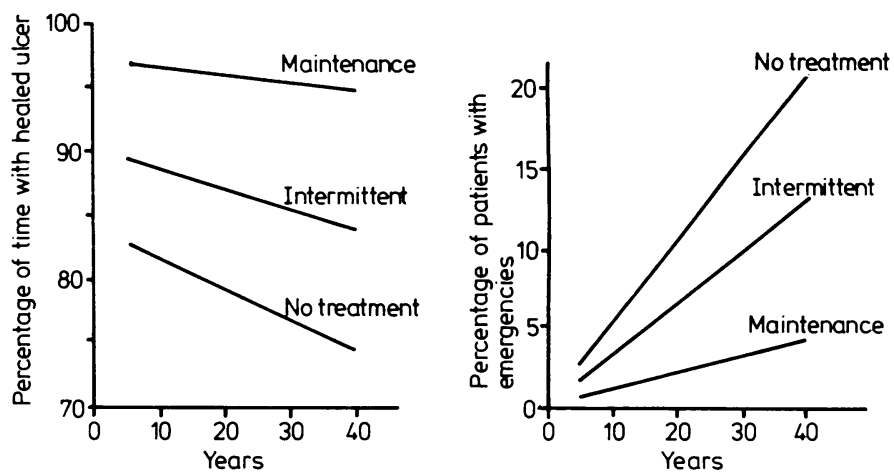

FIG 2-Effect of medical treatment of duodenal ulcer on proportion of time spent with healed ulcer in unoperated patients (left) and on proportion of patients undergoing emergency operations (right).
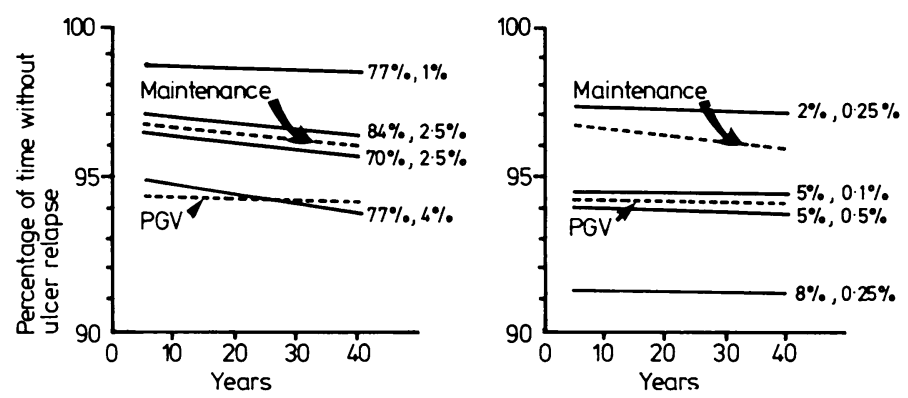

FIG 3-Sensitivity analysis of maintenance treatment (left) and proximal gastric vagotomy (PGV; right). Time without relapse refers to healed duodenal ulcer in unoperated stomach and Visick grades I-III. Interrupted lines denote baseline assumptions of maintenance treatment and of proximal gastric vagotomy. Baseline healing rate of $77 \%$ and recurrence rate of $2.5 \%$ under maintenance treatment were varied from $70 \%$ to $84 \%$ and from $1 \%$ to $4 \%$. Baseline fraction of $5 \%$ in patients with Visick grade IV and recurrence rate of $0.25 \%$ after proximal gastric vagotomy were varied from $2 \%$ to $8 \%$ and from $0.1 \%$ to $0.5 \%$

whereas with maintenance treatment deaths due to complications of the ulcer accumulate with time. The proportion of patients with unsatisfactory results after emergency operations will be $0.3 \%$. Doubling the incidence of complications and emergency operations leaves the proportion of healed ulcers more or less unchanged (fig 5).

After proximal gastric vagotomy $99 \%$ of the time is spent free of recurrent ulcer. Nevertheless, when the proportion of unsatisfactory operative results (Visick grade IV) is disregarded in the fraction of healed ulcer the fractions change in favour of maintenance treatment (fig 3 (right)). With Visick grades I-III being possible in $98 \%$ of patients proximal gastric vagotomy would surpass maintenance treatment under baseline assumptions. The outcome of surgery remains predominantly insensitive to changes in the postoperative recurrence rate. 


\section{Discussion}

This simple model used to predict the outcome of treatment of duodenal ulcer shows that maintenance treatment far surpasses intermittent treatment. Although intermittent treatment improves the fraction of healed ulcers as compared with no treatment, frequent recurrences remain a risk for patients receiving intermittent treatment. Maintenance treatment proves to be better than proximal gastric vagotomy. The advantage of maintenance treatment over vagotomy also prevails under the worst assumptions about rate of ulcer recurrence. Proximal gastric vagotomy may be

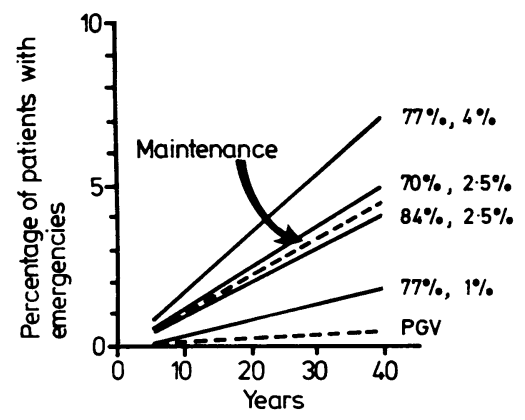

FIG 4-Sensitivity analysis of maintenance treatment: impact of changes in monthly healing and recurrence rates on proportion of emergencies. Same variations as in fig 3 left) considered. (PGV = Proximal gastric vagotomy.)
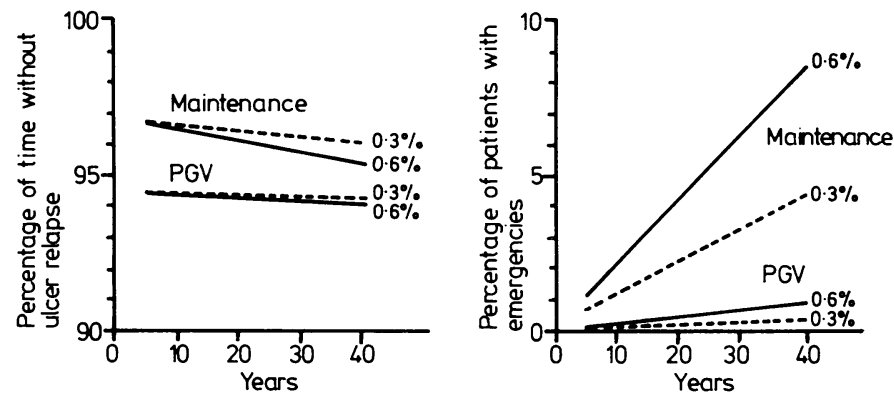

FIG 5-Sensitivity analysis of maintenance treatment: impact of doubling the incidence of emergency operations from baseline $0.3 \%$ to $0.6 \%$ per month per recurrent ulcer.

superior to maintenance treatment only in surgical centres of excellence with extremely low postoperative morbidity. In the case of optimal assumptions for both therapeutic strategies maintenance treatment again comes off slightly better than proximal gastric vagotomy.

The model used in this study was derived from a model of medical treatment for chronic duodenal ulcer originally developed by Pounder. ${ }^{3}$ Though he did not describe it so explicitly, his model corresponds to a Markov chain of two states with transitions only between healed and recurrent ulcer being considered. The present model does not consider risks and adverse effects of long term continuous $\mathrm{H}_{2}$ blockade. ${ }^{23-25}$ Owing to the low incidence of severe side effects my results would not be modified by including side effects as an additional state of the Markov chain for less than one per 1000 patients. Since no reliable data exist on the risk of gastric cancer after prolonged inhibition of acid secretion by either type of treatment ${ }^{21}{ }^{26}$ this question was not addressed in the analysis.

Surgeons tend to emphasise the low rate of postoperative complications and morbidity after proximal gastric vagotomy. By contrast, maintenance treatment is associated with the continuing risk of costly complications due to recurrent ulcers. These arguments are validated by the present model. Even with maintenance treatment the rate of complications and the number of deaths related to ulcers remain higher than with proximal gastric vagotomy. Nevertheless, because the few deaths in patients given proximal gastric vagotomy occur at the initiation of treatment the loss in life years with maintenance treatment exceeds that of proximal gastric vagotomy only after 20 years. The morbidity after vagotomy-albeit less than with any other type of gastric surgery-outweighs the advantage of a lower rate of recurrent ulceration leading to fewer complications of ulcer disease. These arguments remain insensitive to changes in the assumptions underlying the present model.

This study was supported by a grant from the Deutsche Forschungsgemeinschaft, grant No So $172 / 1-1$.

\section{References}

1 Beck JR, Pauker SG. The Markov process in medical prognosis. Medical Decision Making 1983;3:419-58.

2 Goligher JC. The comparative results of different operations in the elective treatment of duodenal ulcer. Br f Surg 1970;57:780-3.

3 Pounder RE. Model of medical treatment for duodenal ulcer. Lancet 1981;i:29-30.

4 Bonnevie O. Survival in peptic ulcer. Gastroenterology 1978;75:1055-60.

5 Fry J. Peptic ulcer: a profile. Br Med f 1964;ii:809-12.

6 Krag E. Long-term prognosis in medically treated peptic ulcer. Acta Med Scand 1966;180:657-70.

7 Puivertaft CN. Comments of the incidence and natural history of gastric and duodenal ulcer. Postgrad Med f 1968;44:597-602.

8 Dronfield MW, Atkinson M, Langman MJS. Effect of different operation policies on mortality from bleeding peptic ulcer. Lancet 1979;i:1126-8.

9 Donaldson GA, Jarrett F. Perforated gastroduodenal ulcer disease at the Massachusetts General Hospital from 1952 to 1970. Am f Surg 1970;120:306-11

10 Postlethwait RW. Five year follow-up results of operations for duodenal ulcer. Surg Gynecol Obstet 1973;137:387-92.

11 Koffman CG, Hay DJ, Ganguli PC, et al. A prospective randomized trial of vagotomy in chronic duodenal ulceration: 4-year follow-up. Br f Surg 1983;70:342-5.

2 Fraser AG, Brunt PW, Matheson NA. A comparison of highly selective vagotomy with truncal vagotomy and pyloroplasty—one surgeon's results after 5 years. Br $\mathcal{F}$ Surg 1983;70:485-8.

13 DeVries BC, Eeftinck M, Schattenkerk EE, et al. Prospective randomized multicentre trial of proximal gastric vagotomy or truncal vagotomy and antrectomy for chronic duodenal ulcer: proximal gastric vagotomy or truncal vagotomy
results after 5-7 years. Br f Surg 1983;70:701-3.

14 Andersen D, Høstrup H, Amdrup E. The Aarhus county vagotomy trial. II. An interim report on reduction in acid secretion and ulcer recurrence rate following parietal cell vagotomy and selective gastric vagotomy. World J Surg 1978;2:91-100.

15 Berstad A, Aadland E, Bjerke K. Cimetidine treatment of recurrent ulcer after proximal gastric vagotomy. Scand f Gastroenterol 1981;16:891-6.

16 Johnston $\mathrm{D}$. Operative mortality and postoperative morbidity of highly selective vagotomy. $\mathrm{Br}$ Med J 1975;iv:545-7.

17 Bardhan KD. The short- and medium-term treatment of duodenal ulcer with cimetidine. In: Bianchi Porro G, Bardhan KD, eds. Peptic ulcer disease-advances in pathogenesis and treatment. Verona and New York: Cortina International and Raven Press, 1982:85-113.

18 Boyd EJS, Wilson JA, Wormsley KG. Review of ulcer treatment: role of ranitidine. 7 Clin Gastroenterol 1983;5(suppl 1):133-41.

19 Ireland A, Colin-Jones DG, Gear P, et al. Ranitidine $150 \mathrm{mg}$ twice daily vs $300 \mathrm{mg}$ nightly in treatment of duodenal ulcers. Lancet 1984;ii:274-6.

20 Gough KR, Korman MG, Bardhan KD, et al. Ranitidine and cimetidine in prevention of duodenal ulcer relapse. A double-blind, randomised, multicentre, comparative trial. Lancet 1984;ii:659-62.

21 Thompson JC, Wiener I. Evaluation of surgical treatment of duodenal ulcer: short- and long-term effects. Clin Gastroenterol 1984;13:569-600.

22 Adami HO, Enander LK, Enskog L, Ingvar C, Rydberg B. Recurrences 1 to 10 years after highly selective vagotomy in prepyloric and duodenal ulcer disease. Ann Surg 1984;199:393-9.

23 Gifford LM, Aeugle ME, Myerson RM, Tannenbaum PJ. Cimetidine postmarket outpatient surveillance program. Interim report on phase I. JAMA 1980;243:1532-5.

24 Davis TG, Pickett DL, Schlosser JH. Evaluation of a worldwide spontaneous reporting system with cimetidine. FAMA 1980;243:1912-4

25 Colin-Jones DG, Langman MJS, Lawson DH, Vessey MP. Postmarketing surveillance of the safety of cimetidine: 12 month mortality report. Br Med f 1983;286:1713-6.

26 Colin-Jones DG, Langman MJS, Lawson DH, Vessey MP. Cimetidine and gastric cancer: preliminary report from postmarketing surveillance study. $\mathrm{Br} \mathrm{Med} \mathrm{f} \mathrm{1983;285:1311-3.}$

(Accepted 7 fanuary 1985

\section{Is there any statistical evidence that cancer is commoner in single people?}

Total cancer risk is little related to marital status. Thus in a five year follow up of a $1 \%$ sample from the 1971 census, Fox and Goldblatt observed 270 cancer deaths among single men and 334 cancer deaths among single women, ${ }^{1}$ figures that were close to those, 267 and 355 respectively, expected for men and women as a whole. For women, however, there is evidence of a relationship of marital status to risk of certain types of cancer, marriage protecting against cancer of the breast and cancer of the body of the uterus at later ages, but predisposing to cancer of the cervix. ${ }^{2}-\mathrm{P}$ N LEE, consultant in statistics and adviser in epidemiology and toxicology, London.

1 Fox AJ, Goldblatt PO. Longitudinal study. Socio-demographic monality differentials. London: HMSO, 1982. Office of Population Censuses and Surveys. (Series LS No 1.)

2 Registrar General. Decennial supplement. England and Wales 1961. Occupational mortality tables. London: HMSO. 1971 